\title{
Evening Primrose (Oenothera biennis) Oil in Management of Female Ailments
}

\author{
Mohaddese Mahboubi \\ Medicinal Plants Research Department, Research and Development, TabibDaru Pharmaceutical Company, Kashan, Iran
}

Oenothera biennis with the common name of "evening primrose" is containing a valuable fixed oil with commercial name of EPO. Evening primrose oil has two types of omega-6-fatty acid including linoleic acid $(60 \%-80 \%)$ and $\gamma$-linoleic acid $(8 \%-14 \%)$. Essential fatty acids are considered as essential compounds for body health, especially among women. The aim of this study was to evaluate the efficacy of evening primrose oil in the management of women ailments. The document was prepared by investigation in scientific articles of electronic resources (Google Scholar, PubMed, Science Direct, Wiley, Scopus, and Springer) by keywords of evening primrose oil and women. The results of our investigations showed that evening primrose oil has been the subject of several clinical studies, including premenstrual syndrome (PMS), hot flash, mastalgia, fibroadenomas, gestational diabetes, cervical ripening, and dilation. The major clinical studies are focused on mastalgia, followed by PMS. The results of studies confirmed the evening primrose oil's efficacy in women health, but the immediate response should not be expected from it, therefore, it should be regularly used up to 4 or 6 months.

Key Words: Evening primrose oil, Mastodynia, Premenstrual syndrome

\section{INTRODUCTION}

Oenothera biennis with the common name of "evening primrose" grows in different parts of the world. The reason for calling $O$. biennis as evening primrose is its yellow flowers, which bloom in the evening. Evening primrose oil with commercial name of 'EPO' is a valuable fixed oil, which is extracted from the $O$. biennis seeds. The reputation of evening primrose oil is related to its chemical components. The oil's content of $O$. biennis is up to $25 \%$. Evening primrose oil has two types of omega-6-fatty acid including linoleic acid $(60 \%-80 \%)$ and $\gamma$-linoleic acid $(8 \%-14 \%)$, which are considered as essential fatty acids, which they are not synthesized in the body [1]. The efficacy of evening primrose oil in management of various diseases (atopic eczema, mastalgia, premenstrual syndrome [PMS], diabetic neuropathy, multiple sclerosis, rheumatoid ar- thritis, Sjögren's syndrome, coronary heart disease, renal disease, gastrointestinal disorders, viral infections/ post-viral fatigue, endometriosis, schizophrenia, alcoholism, and dementia) was the subject of large clinical trials [2] and there are some review articles on efficacy of evening primrose oil alone or in combination with other fixed oils, on atopic eczema [3-5], schizophrenia [6], and rheumatologic conditions [7,8], but there are no review articles on the efficacy of evening primrose oil on women health. Evening primrose oil has been a special place for women in the management of female ailments during whole life. In this review article, we evaluated the evening primrose oil potency in the management of women's health on the base of clinical trials.

\section{MATERIALS AND METHODS}

The document was prepared by searching in scientific

Received: December 19, 2018 Revised: March 17, 2019 Accepted: April 7, 2019

Address for Correspondence: Mohaddese Mahboubi, Medicinal Plants Research Department, Research and Development, TabibDaru Pharmaceutical Company, Kashan 8715115779, Iran

Tel: 98-3155541000, E-mail: mahboubi1357@yahoo.com, ORCID: https://orcid.org/0000-0003-4732-7302 
resources (Google Scholar, PubMed, Science Direct, Wiley, Scopus, and Springer) by keywords of evening primrose oil or O. biennis plus women. The data were divided into different sections of PMS, mastalgia, hot flash, fibroadenomas, gestational diabetes, pre-eclampsia, cervical ripening, and dilatation, and were interpreted.

\section{MANAGEMENT WITH EVENING PRIMROSE OIL}

\section{Management of premenstrual syndrome}

PMS is a condition, which is associated with somatic, emotional and behavioral symptoms during the women menstruation. Anxiety, depression, acne, fatigue, and headache are common symptoms of PMS. Insomnia and suicidal thoughts are severe symptoms of premenstrual dysphoric disorders. Menstruating women of $85 \%$ are affected by these symptoms. PMS is characterized by over 150 clinical symptoms (behavioral, psychological, and physical) including cyclical mastalgia, headache, backache, irritability, depression, food carving, and irritable bowel syndrome during the luteal phase of menstrual cycles. Low level of prostaglandin $\mathrm{E}_{1}$, as the result of a deficiency in essential fatty acids causes high sensitivity to prolactin, which produces at ovulation time and increases the high level during the luteal phases [9].

The therapeutic potency of evening primrose oil in the management of PMS is the subject of many clinical trials (Table 1). Linoleic acid promotes prostaglandin synthesis and alleviates PMS. The first report on the efficacy of evening primrose oil in PMS returned to a meta-analysis in 1994. This meta-analysis was performed on seven placebo-controlled clinical trials, which five trials had clear randomization. From these seven randomized clinical trials, only two clinical trials were well-controlled studies, but the small and modest sample size of these two studies limited the conclu- sion on the efficacy of evening primrose oil in PMS. The only best finding of this meta-analysis article is the safety of 3 to $6 \mathrm{~g}$ daily dose of evening primrose oil in volunteers with PMS [10]. In a randomized doubleblind placebo controlled parallel design, the alleviating effect of $180 \mathrm{mg} / \mathrm{d} \gamma$-linoleic acid was compared with the placebo on clinical symptoms of 28 women suffering from PMS in three luteal phases. The patients in the placebo group received edible oil without $\gamma$-linolenic acid. The blood samples in three cycles, duration and severity of symptoms were compared in groups. The levels of stearic acid, oleic acid and dihomo- $\gamma$-linolenic acid, palmitic acid and $\gamma$-linolenic acid in plasma phospholipids had a significant reduction in follicular and luteal phases. Irritable bowel syndrome was the most common symptom of women with PMS, followed by breast swelling, drowsiness, avidity, and facial eruption. After treatment, the patients in $\gamma$-linolenic acid group had higher $\gamma$-linolenic acid and dihomo- $\gamma$-linolenic acid in plasma phospholipids compared to the placebo group. The severity and duration of PMS (physical, mental, and social), irritability improved in the $\gamma$-linolenic acid group compared to the placebo group $(P$ $<0.05$ ) [11]. In another randomized placebo-controlled trial, evening primrose oil was evaluated on 80 women with PMS according to Diagnostic and Statistical Manual of Mental Disorders, Fourth Edition Text Revision (DSM-IV-TR) criteria. The randomized patients of two groups received a daily dose of $1.5 \mathrm{~g}$ evening primrose oil or placebo for three months. Compared to before intervention, evening primrose oil significantly changed the PMS severity scores after the intervention, while no significant difference was observed in PMS scores after treatment with placebo. The symptom severity scores reduced from $53.2 \pm 14.31$ to $33.62 \pm 16.94$ after three months administration of evening primrose oil, while these amounts were $53.38 \pm 13.93$ and $50.27 \pm 16.94$ in placebo groups. A significant difference in PMS symptom severity scores was observed between placebo

Table 1. Clinical Trials on evening primrose oil (EPO) in management of premenstrual syndrome (PMS)

\begin{tabular}{|c|c|c|}
\hline Trial/ailments & Intervention/d & Results \\
\hline Meta-analysis on 7 placebo-controlled trial, PMS [10] & 3-6 g EPO & $\begin{array}{l}\text { Safety of EPO } \\
\text { No scientific results due to small sample size }\end{array}$ \\
\hline $\begin{array}{l}\text { Randomized double-blind placebo controlled parallel } \\
\text { design, PMS [11] }\end{array}$ & 180 mg GLA, placebo & $\begin{array}{l}\text { Increase in GLA, DGLA in plasma phospholipid } \\
\text { Improvement of PMS severity and duration }\end{array}$ \\
\hline Placebo randomized control trial, PMS [12] & $1.5 \mathrm{~g} \mathrm{EP0}$, placebo & Significant reduction in PMS severity score \\
\hline
\end{tabular}

GLA: $\gamma$-linolenic acid, DGLA: dihomo- $\gamma$-linolenic acid. 
and evening primrose groups after three months of interventions $(P<0.001)$ [12]. The results of the above clinical studies showed the efficacy and safety of evening primrose oil in the management of PMS during menstruation.

\section{Management of mastalgia}

The women of $70 \%$ complain of breast pain at some stages of their life. Breast pain or mastalgia is a common distressing ailment among ladies in reproductive ages. Cyclical breast pain is as the result of changing in hormone during the menstrual cycle, while noncyclical breast pains are not linked to menstrual cycle [13]. The deficiency in $\gamma$-linolenic acid or its derivatives makes the breast tissues sensitive to sex hormones, which is associated with breast pain [14].

The most clinical trials on women ailments have been focused on the efficacy of evening primrose oil in cycli- cal mastalgia (Table 2). One-hundred women (15-35 years old) with moderate to severe mastalgia were recruited for an open, non-randomized, comparative clinical study, and were evaluated according to Cardiff breast pain score (CBS). The patients received $100 \mathrm{mg}$ oral danazol, or $500 \mathrm{mg}$ evening primrose oil, twice daily for a period of three months. The responses to treatments were evaluated at baseline, 4 and 12 weeks after treatments. There was no significant difference between the two groups after 4 and 12 weeks of treatments. The reported distressing adverse effects were reported in $32 \%$ and $12 \%$ of women in danazol and evening primrose oil, respectively [15].

In single-blinded clinical study on 61 women suffering from cyclical mastalgia (18-40 years old), who were randomly divided in two groups of $3 \mathrm{~g}$ daily oral evening primrose oil $(n=31)$ or $600 \mathrm{mg}$ daily oral vitamin $\mathrm{E}(\mathrm{n}=30)$ and were evaluated according to CBS

Table 2. Clinical trials on evening primrose oil (EPO) in management of mastalgia

\begin{tabular}{|c|c|c|}
\hline Trial/ailments & Intervention & Results \\
\hline Prospective clinical trial [18] & $\begin{array}{l}6 \text { EPO capsule }(240 \mathrm{mg} / \mathrm{d} \text { GLA }) \\
\text { For } 6 \text { mo }\end{array}$ & Overal response $97 \%$ \\
\hline $\begin{array}{l}\text { Double blind placebo controlled parallel multi- } \\
\text { center clinical trial }(n=555)[21]\end{array}$ & $\begin{array}{l}4 \mathrm{~g} \text { daily EPO plus antioxidant, EPO plus place- } \\
\text { bo antioxidant, placebo EPO plus antioxidant, } \\
\text { placebo EPO plus placebo antioxidant }\end{array}$ & No effectiveness of EPO in mastalgia \\
\hline Randomized double blind [24] & $\begin{array}{l}\text { Piroxicam gel } 0.5 \% \text {, twice a day or } 1 \mathrm{~g} \text { daily } \\
\text { EPO } \\
\text { For } 3 \mathrm{mo}\end{array}$ & $\begin{array}{l}\text { Piroxicam gel: excellent response }(56 \%) \text {, sub- } \\
\text { stantial response }(35 \%) \text {, poor response }(8 \%) \\
\text { EP0 capsule: substantial response }(64 \%), \text { poor } \\
\text { response }(32 \%)\end{array}$ \\
\hline $\begin{array}{l}\text { Open non-randomized comparative clinical study } \\
\text { [15] }\end{array}$ & $\begin{array}{l}1 \mathrm{~g} \mathrm{EPO} / \mathrm{d}, 100 \mathrm{mg} \text { danazol } \\
\text { For } 3 \mathrm{mo}\end{array}$ & $\begin{array}{l}\text { Excellent response } \\
4 \text { wk ( } 36 \% \text { vs. } 44 \%) \\
12 \text { wk }(68 \% \text { vs. } 76 \%) \\
\text { Adverse effects }(20 \% \text { vs. } 24 \%)\end{array}$ \\
\hline Randomized clinical study [20] & $\begin{array}{l}5 \mathrm{mg} / \mathrm{d} \text { bromocriptine plus } 2 \mathrm{~g} / \mathrm{d} \text { EPO }(\mathrm{n}=36) \\
\text { LILT }(\mathrm{n}=40)\end{array}$ & $\begin{array}{l}\text { Response to treatment } \\
63.9 \% \text { vs. } 82.5 \%\end{array}$ \\
\hline Single-blind clinical study [16] & $\begin{array}{l}3 \mathrm{~g} \mathrm{EP} 0 / \mathrm{d}(\mathrm{n}=31), 600 \mathrm{mg} \text { vitamin } \mathrm{E}(\mathrm{n}=30) \\
\text { For } 1 \mathrm{mo}\end{array}$ & $\begin{array}{l}\text { Reduction in pain severity } \\
61.3 \% \text { vs. } 26.7 \%\end{array}$ \\
\hline $\begin{array}{l}\text { Double-blind randomized placebo controlled trial } \\
\text { [17] }\end{array}$ & $\begin{array}{l}1,200 \mathrm{IU} \text { vitamin } \mathrm{E}(\mathrm{n}=21), 3 \mathrm{~g} / \mathrm{d} \text { EPO }(\mathrm{n}=21) \text {, } \\
\text { vitamin } \mathrm{E}+\mathrm{EPO}(\mathrm{n}=21), \text { placebo }(\mathrm{n}=22) \\
\text { For } 6 \mathrm{mo}\end{array}$ & No significant effect \\
\hline $\begin{array}{l}\text { Double-blind randomized placebo controlled trial } \\
\text { [19] }\end{array}$ & $\begin{array}{l}2 \mathrm{~g} / \mathrm{d} \text { EPO }(n=25), 400 \mathrm{IU} \text { vitamin E, EPO plus } \\
\text { vitamin E, placebo } \\
\text { For } 6 \mathrm{mo}\end{array}$ & $\begin{array}{l}\text { A significant difference between intervention } \\
\text { groups with placebo }\end{array}$ \\
\hline $\begin{array}{l}\text { Double-blind randomized placebo controlled } \\
\text { trial, cyclical mastalgia [26] }\end{array}$ & $\begin{array}{l}2 \mathrm{~g} / \mathrm{d} \text { EPO }(n=86) \\
\text { Centchroman }(n=67)\end{array}$ & $23 \%$ vs. $68 \%$ response to treatment \\
\hline $\begin{array}{l}\text { A randomized, double-blind factorial controlled } \\
\text { trial [22] }\end{array}$ & $\begin{array}{l}3 \mathrm{~g} \text {; 1) fish oil- control oil, 2) EPO-control oil, 3) } \\
\text { fish oil-EPO, 4) both control oils (wheat germ } \\
\text { oil plus corn oil) }\end{array}$ & $\begin{array}{l}\text { No priority of EPO or fish oil than that of whea } \\
\text { germ oil or corn oil in treatment of mastalgia }\end{array}$ \\
\hline
\end{tabular}

GLA: $\gamma$-linolenic acid, LILT: low-intensity laser therapy. 
and the severity of pain. The patients received medications, three times a day for one month at the beginning of their menstruation cycle. Intervention with evening primrose oil or vitamin E significantly reduced the severity of pain $(61.3 \%$ vs. $26.7 \% ; P<0.05)$ [16].

Eighty-five women with cyclical mastalgia were randomly divided into four groups of 1,200 IU/d vitamin $\mathrm{E}$ $(\mathrm{n}=21), 3 \mathrm{~g} / \mathrm{d}$ evening primrose oil $(\mathrm{n}=21), 1,200 \mathrm{IU} /$ $\mathrm{d}$ vitamin E plus $3 \mathrm{~g} / \mathrm{d}$ evening primrose oil $(\mathrm{n}=21)$, or placebo $(n=22)$ for 6 months and were evaluated by modified McGill pain questionnaire. The results of this pilot study showed no significant reduction in cyclical mastalgia in three intervention groups but showed a trend toward a benefit with evening primrose oil, vitamin $\mathrm{E}$ or their combination [17].

In another prospective clinical trial on sixty-six women (17-49 years) with disturbing cyclical mastalgia, and having single breast surgeon, the patients were recommended to use six evening primrose oil capsules for 3 months. Treatments continued for 3 and 6 months in patients with unresolved mastalgia. The median duration of pain before treatment was 12 months on the base of CBS, and $40 \%$ of women experienced mastalgia for more than 12 months, while, only $18 \%$ administered analgesics for their mastalgia. After treatment, the overall response to evening primrose oil was $97 \%$ after 6 months of treatments [18].

The efficacy of evening primrose oil was evaluated on 100 women with cyclic mastalgia and the patients were divided into four groups $(\mathrm{n}=25)$ and received $2 \mathrm{~g}$ daily evening primrose oil, or $400 \mathrm{IU}$ vitamin $\mathrm{E}$, or $2 \mathrm{~g}$ daily evening primrose oil plus 400 IU vitamin E or placebo for 6 months. The difference between the three treatment groups was not significant $(P>0.05)$, but the difference between intervention groups and placebo was statistically significant [19].

In a double-blind clinical study on 80 Egyptian women with cyclical mastalgia, who were randomly divided into two groups and received $5 \mathrm{mg}$ daily bromocriptine plus $2 \mathrm{~g}$ daily evening primrose oil $(\mathrm{n}=36)$ or low-intensity laser therapy (helium-neon laser plus infra-red diode laser) $(\mathrm{n}=40)$. The visual analogue score (VAS) and plasma cortisol level were evaluated in patients. The response to treatment by evening primrose oil plus bromocriptine and laser therapy was $63.9 \%$ and $82.5 \%$, respectively. Patients of $37.5 \%$ reported adverse effects (nausea, epigastric discomfort, vomiting, and dizziness) after administration of bromocriptine [20].

A double-blind placebo-controlled parallel multi- center clinical trial on 555 women with moderate to severe mastalgia, the patients randomly allocated in four groups of $\gamma$-linolenic acid plus antioxidants or placebo $\gamma$-linolenic acid plus antioxidants, or $\gamma$-linolenic acid plus placebo antioxidant or placebo $\gamma$-linolenic acid and placebo antioxidants for four menstrual cycles. The $\gamma$-linolenic acid of $320 \mathrm{mg}$ daily was prepared by 4 $\mathrm{g}$ daily evening primrose oil capsule. Evening primrose oil capsule was containing $10 \mathrm{mg}$ natural vitamin $\mathrm{E}$. The antioxidant capsule was containing $3 \mathrm{mg} \beta$-carotene, $100 \mathrm{mg}$ vitamin $\mathrm{C}, 25 \mathrm{mg}$ vitamin $\mathrm{B}_{6}, 10 \mathrm{mg}$ zinc, 10 $\mathrm{mg}$ niacin, and $455 \mu \mathrm{g}$ selenium. After 1-month washout period, the patients received evening primrose oil for eight menstrual cycles, randomized to active or placebo antioxidants according to the parallel phase. From 555 patients, $77 \%$ and $69 \%$ completed the blinded and open phases of a clinical study, respectively. Breast pain scores improved in 4 groups at the end of treatments. The difference among the four groups was not significant $(P>0.05)$. The patient's VAS measurements and patients assessments showed improvement in two phases. Nausea was the most common adverse event during treatment [21].

In another randomized clinical trial on 135 patients with mastalgia, who randomly received $30 \mathrm{mg}$ centchroman (ormeloxifene; $\mathrm{n}=67$ ) or $3 \mathrm{~g} / \mathrm{d}$ evening primrose oil $(\mathrm{n}=68)$ for 6 months. After 6 months, $68 \%$ and $23 \%$ of patients had a complete response to treatment $(P<0.05)$ and centchroman had a significant effect on breast pain relief and nodularity higher than evening primrose oil group [22].

A randomized, double-blind factorial controlled trial on 120 women with severe chronic mastalgia, who were randomly divided into four groups of 1) fish oilcontrol oil, 2) evening primrose oil- control oil, 3) fish oil- evening primrose oil, and 4) both control oils (wheat germ oil plus corn oil). The decrease in percentage days with mastalgia after 6-month treatment were $12.3 \%, 13.8 \%$ for evening primrose oil and its control $(P=0.73)$, while these amounts were $15.5 \%, 10.6 \%$ for fish and its control $(P=0.28)$ [23]. In another study, the efficacy, safety, and response of evening primrose oil in the treatment of mastalgia was compared with topical non-steroidal anti-inflammatory drugs (NSAIDs). Fifty women (15-50 years) with moderate to severe mastalgia were divided into two groups of piroxicam gel 0.5\% (twice a day for 3 months) and $1 \mathrm{~g}$ daily evening primrose oil. After 12 weeks of treatment with NSAIDs, $56 \%, 35 \%$ and $8 \%$ of patients had excellent, substantial 
and poor responses, respectively. In evening primrose oil, $64 \%$ and $32 \%$ of patients had substantial or poor responses to treatment. Patients of $4 \%$ reported side effects with evening primrose oil (nausea and altered taste) [24]. Among 10 clinical studies, 7 clinical studies showed the priority of evening primrose oil than other treatments in the management of mastalgia. Therefore, evening primrose oil can be used as a safe and effective treatment for mastalgia in women.

\section{Management of hot flash}

Evening primrose oil is the most popular treatment as complementary and alternative medicine among 1,296 menopausal women in Sydney. Women of $66.3 \%$ found it as an effective treatment in menopause symptoms [25]. The most commonly experienced symptom of menopause is hot flash.

The efficacy of $500 \mathrm{mg}$ evening primrose oil capsule or placebo was evaluated in a randomized, doubleblind placebo-controlled trial on 56 menopausal women (45-59 years old) with hot flashes on the base of Hot Flash Related Daily Interference Scale (HFRDIS) questionnaire before and after treatments. The patients received 90 capsules $500 \mathrm{mg}$ for 6 weeks. The hot flash frequency, severity and duration percent were $39 \%, 42 \%$, and $19 \%$ for evening primrose oil, while these amounts were $32 \%, 32 \%$, and $18 \%$ in the placebo group, respectively. The significant difference was observed between the hot flash severity percent of evening primrose oil and placebo groups $(P<0.05)$. HFRDIS scores improved in two groups, but the social activities, sexuality, and relation with others were significantly higher in evening primrose oil than that of placebo $(P$ $<0.05$ ) [26]. Small sample size influences the result of the study, so it can be the limitation of the above study, also hot flashes is highly dependent the self-evaluation, therefore, conclusion on response to treatment is difficult.

\section{Management of fibroadenomas}

Fibroadenomas is benign noncancerous tumor in breast, which occurs often in women with the age of 15 to 35 years old. These solid breast lumps are usually painless, round with distinct smooth borders, which can easily move. The etiology of fibroadenomas is unknown, but the reproductive hormones may be involved in fibroadenomas. No treatments are required in many cases, but some patients choose surgical removal of breast lumps. In one clinical study on women with fibroadenomas (22-49 years old), who received a daily dose of $4 \mathrm{~g}$ evening primrose oil $(\mathrm{n}=23)$ or placebo ( $\mathrm{n}$ =16) for 6 months, the clinical size of breast lump was measured by surgeon and ultrasound measurement after and before treatments. In spite of satisfying the patients from treatment with $4 \mathrm{~g}$ evening primrose oil for 6 months, there was no significant difference in means of fibroadenomas size between evening primrose oil and control group after measuring by ultrasound ( $P$ $=0.6$ ). The reduction in fibroadenomas size was $52 \%$ and $42 \%$ in evening primrose oil and control groups, respectively [27]. The results of the only clinical study disapproved the efficacy of evening primrose oil in the treatment of fibroadenomas.

\section{Management of gestational diabetes}

Gestational diabetes develops during pregnancy. The high blood sugar in gestational periods of pregnant women can effect on pregnancy and baby's health. After delivery, gestational pregnancy returns to normal level soon.

In a randomized double-blind placebo controlled clinical trial, the efficacy of $1 \mathrm{~g}$ evening primrose oil and 1,000 IU vitamin D supplements $(\mathrm{n}=30)$ in comparison with placebo for 6 weeks on women with gestational diabetes was evaluated on biochemical variables at baseline and after treatment. The results showed supplement with evening primrose oil and vitamin D caused a significant reduction in serum high sensitivity C-reactive protein level and malondialdehyde, while the increase in plasma nitric oxide and total antioxidant capacity level was observed in evening primrose oil plus vitamin D compared with placebo [28]. Therefore, women with gestational diabetes can benefit from the antioxidant activities of evening primrose oil during their pregnancy.

\section{Management of pre-eclampsia}

Pre-eclampsia is a common dangerous complication of pregnancy, which is associated with high vasoconstriction, plate aggregation, reduction in uteroplacental blood flow and premature delivery. A hundred and fiftiy pregnant primiparous and multiparous women in the first 4 months of pregnancy were randomly divided into three groups of placebo group, evening primrose oil plus fish oil and magnesium oxide group. The patients in the experimental group received 8 capsules of evening primrose oil plus fish oil per day for 30 days, which each capsule was containing $37 \mathrm{mg} \gamma$-linolenic 
acid, $18 \mathrm{mg}$ eicosapentaenoic acid and $10 \mathrm{mg}$ docosahexaenoic acid. The placebo groups received olive oil and the patients in the magnesium group received daily two tablets $500 \mathrm{mg}$ for 30 days. Pre-eclampsia was defined as simultaneous occurrence of edema, hypertension, or proteinuria during the pregnancy. Vomiting and diarrhea were significantly greater in fatty acid supplement and magnesium oxide groups, respectively. The patients in groups fatty acid and magnesium oxide had greater qualitative improvement conditions in 6 months of pregnancy, compared to the placebo group. The weight gain between 1 st and 3rd trimesters was significantly higher in fatty acid supplemented and placebo groups than that of magnesium oxide. The pregnancy-associated hypertension was lower in magnesium supplemented group, while the placebo group had more cases of hypertension. The lower cases of edema were observed in fatty acid supplemented group $(\mathrm{n}=13)$ or magnesium oxide group $(\mathrm{n}=12)$ compared to the placebo group $(\mathrm{n}=29)$. Proteinuria was distributed among three groups. Pre-eclampsia was occurred in 5 cases of placebo groups, followed by fatty acid supplemented group $(\mathrm{n}=2)$ and magnesium oxide ( $\mathrm{n}$ $=2$ ). There was no significant difference between baby's conditions (skin color, heart rate, respiratory effort, and muscle tone) among the three groups. Birth weight was better in fatty acid supplemented group and magnesium oxide group [29]. Evening primrose oil is suitable for pre-eclampsia during pregnancy without any adverse effects.

\section{Management of cervical ripening and dilatation}

Midwives used evening primrose oil as a cervical ripening agent for shortening the labor and reducing the incidence of postdates pregnancies. Evening primrose oil with prostaglandins $\mathrm{E}_{1}$ and $\mathrm{E}_{2}$ precursors has relaxant activity on smooth muscle, which changes cervical vascular tone and consistency. The cervical dilation and effacement affected by prostaglandins [30]. The efficacy of evening primrose oil capsule as the cervical ripening agent was evaluated on thirteen patients with an average age of $27 \pm 6$ years and mean age of gestation $40 \pm 1$ weeks by evaluating Bishop's score before and 4 hours after intervention. The interventions were performed by intra-vaginal insertion of six capsules of $500 \mathrm{mg}$ evening primrose oil. Women of $54 \%, 15 \%$ and $31 \%$ were nulliparous, primiparous, and multiparous, respectively. The Bishop's scores were changed 4 hours after insertion of evening primrose oil capsules and these changes were significant $(P=0.001)$. The patients of $85 \%$ had an improvement in Bishop scores 4 hours after intra-vaginal insertion of evening primrose oil. Bishop scores for $31 \%$ of patients were higher than 4. Dilation $(P=0.027)$, effacement $(P=0.006)$, and consistency $(P=0.002)$ were the specific components of Bishop scores with significant changes, other components of Bishop scores, such as position $(P=0.08)$, and station $(P=0.17)$ had no changes. The patients of $85 \%$ had significant cervical dilation and effacement, based on the clinical changes. The patients of $31 \%$ had vaginal delivery, while $69 \%$ of patients had cesarean section, including nonreassuring fetal status (46\%), arrest in cervical dilation (15\%), and intra-amniotic infection (8\%) [31]. The other clinical study, the efficacy of oral evening primrose oil was evaluated on length of pregnancies and intrapartum outcomes of 108 lowrisk nulliparous women in retrospective quasi-experimental clinical study. The patients were divided into two groups of $500 \mathrm{mg}$ evening primrose oil or control groups and the patients received evening primrose oil or nothing from 37th gestational weeks until child delivery. The results of the study showed oral feeding with oral daily of evening primrose oil did not reduce the length of labor time, and also increased the risk of the protracted active phase, the arrest of descent and vacuum extractor utilization. The use of patients' records to asses outcome variables, no strict procedure for defining the onset of labor or latent phase is the limitation of this study [32].

The efficacy of $500 \mathrm{mg}$ evening primrose oil on cervical ripening and dilatation of thirty-six non-menopausal patients and 14 menopausal patients was evaluated before hysteroscopy. The patients were randomly divided into two groups of evening primrose oil or placebo. The patient received $1 \mathrm{~g}$ soft capsules 6 to 8 hours before hysteroscopy via posterior vaginal fornix. The total dilation time, uterine cervicovaginal complication and the adverse effects related to treatments were evaluated. Application of evening primrose oil reduced the total cervical dilation time ( $P=0.003$ ), also, evening primrose oil caused a greater first Hegar size or force for cervical dilation compared to the placebo group $(P$ $=0.002)$. No adverse effects or uterine cervicovaginal complications were reported during the study [33].

The effect of intra-vaginal evening primrose oil was compared with intra-cervical laminaria in ease of cervical dilation prior to hysteroscopy. The patients in the laminaria group received treatment 12 hours before 
hysteroscopy, while the patients in evening primrose oil received 6 soft capsules 6 hours prior and 4 capsules 1 hour before hysteroscopy. Cervical dilation and time to reach Hegars $10 \mathrm{~mm}$ were recorded for two groups. The initial cervical dilations were 5 and $7 \mathrm{~mm}$ in laminaria and evening primrose oil group and median time to Hegars $10 \mathrm{~mm}$ were 5 minutes and 45 seconds for laminaria, while the corresponding time for evening primrose oil was 1 minute and 57 seconds. Cervical dilation was good and easy for laminaria and evening primrose oil groups, respectively. The patients in evening primrose oil group had no pain, while the other group had tolerable pain. The results of this clinical trial showed better cervical dilatation and required less time for evening primrose oil group, rather than laminaria [34]. The use of intra-vaginal evening primrose oil has cervical ripening effects in women and can be used prior to hysteroscopy or childbirth.

\section{CONCLUSION}

The results of clinical studies on the efficacy of evening primrose oil on women's health showed its therapeutic potential for PMS, hot flash, gestational diabetes, and cervical ripening (Fig. 1). The most relevant clinical studies were performed on mastalgia and in spite of confusing results, the priority of evening primrose oil than that of chemical synthetic drug or placebo has been confirmed in the majority of clinical studies of mastalgia. There is one clinical study on fibroadenomas, which showed no efficacy related to evening primrose oil for it.

Totally, due to the needs of the body for essential fatty acids, on the base of 250 to $600 \mathrm{mg} / \mathrm{d} \gamma$-linolenic acid, the daily dose of evening primrose oil will be 2.6 to 5.2 $\mathrm{g} / \mathrm{d}$ for mastalgia. Evening primrose oil is considered as the safe oil, but it should be avoided in patients, who take phenothiazine in schizophrenics $[35,36]$. There are no adverse effects related to $2.5 \mathrm{~mL} / \mathrm{kg}$ daily evening primrose oil for 52 weeks in mice or 104 weeks in rats, respectively. No adverse effects were observed for 5 $\mathrm{mL} / \mathrm{kg}$ daily dose of evening primrose oil for 52 weeks [37]. Evening primrose oil has protective effect against teratogenic potential of alcohol in pregnant women and also is an effective component for topical female products for vaginal uses. Evening primrose oil likely interacts with anti-platelet and anticoagulant drugs, but there are no scientific reports on it. One hypothesis narrates $\gamma$-linolenic acid forms prostaglandin $E_{1}$ and thromboxane. The priority for prostaglandin $E_{1}$ than thromboxane inhibits the platelet aggregation. Some patients complain from bloating and gastrointestinal problems after administration of evening primrose oil [35]. Nausea, headache, and diarrhea are the occasional effects related to evening primrose oil [1]. The immediate results should not be expected from evening prim-

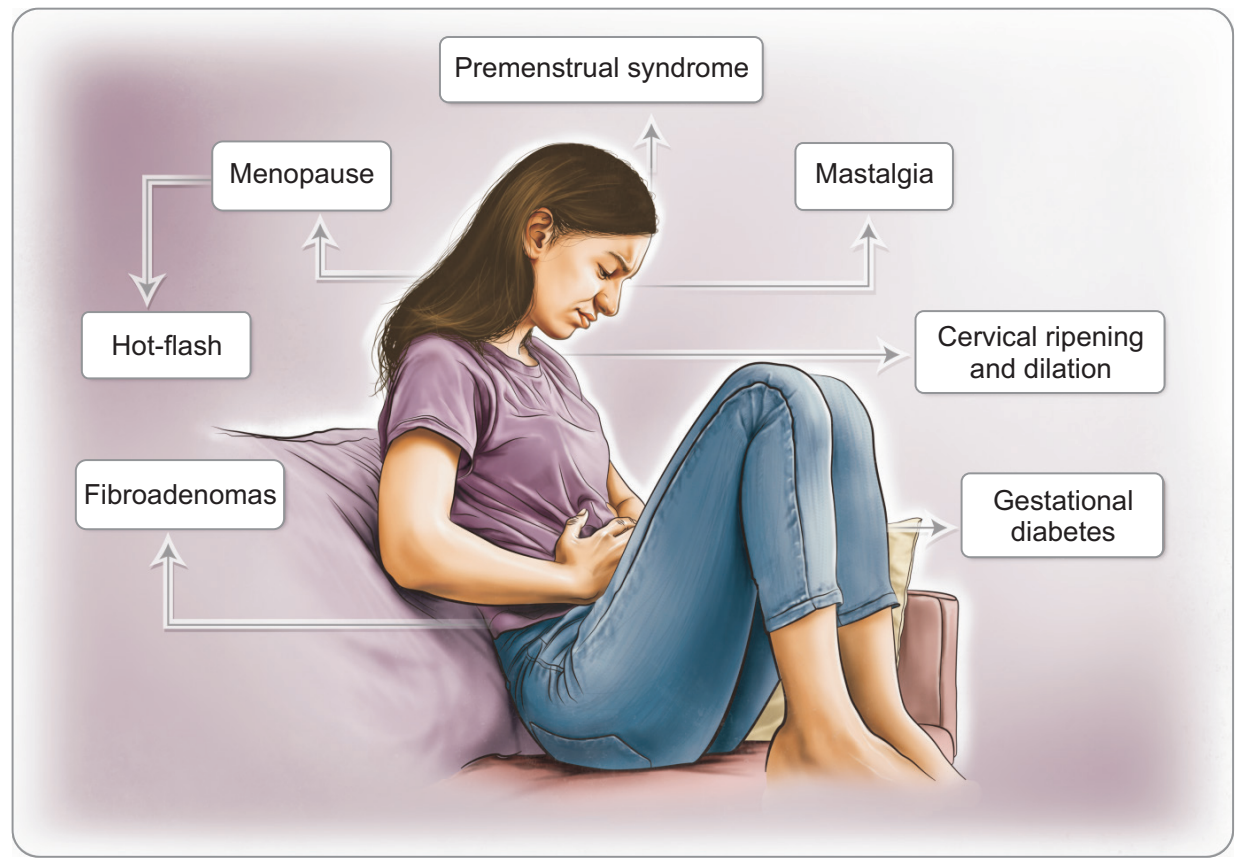

Fig. 1. The potential of evening primrose oil in management of women ailments. 
rose oil; therefore, it should be regularly used up to 4 months. Evening primrose oil is used as lactation aid and its recommended dose is 4 capsules $500 \mathrm{mg}$, twice daily every 12 hours. The capsules should be taken with food, milk or liquid. Designing the large multi-center clinical trials on the effectiveness of evening primrose oil on different ailments among women is needed for future studies.

\section{ACKNOWLEDGMENTS}

This study was supported by TabibDaru Pharmaceutical Company.

\section{CONFLICT OF INTEREST}

No potential conflict of interest relevant to this article was reported.

\section{REFERENCES}

1. Barrett M. The handbook of clinically tested herbal remedies. Birmingham (NY): The Haworth Herbal Press'; 2004.

2. Barnes J, Anderson LA, Phillipson JD, Newall CA. Herbal medicines: a guide for healthcare professionals. London: Pharmaceutical Press; 2002

3. Bamford JT, Ray S, Musekiwa A, van Gool C, Humphreys R, Ernst E. Oral evening primrose oil and borage oil for eczema. Cochrane Database Syst Rev 2013; (4): CD004416.

4. Morse NL, Clough PM. A meta-analysis of randomized, placebocontrolled clinical trials of Efamol evening primrose oil in atopic eczema. Where do we go from here in light of more recent discoveries? Curr Pharm Biotechnol 2006; 7: 503-24.

5. Kerscher MJ, Korting HC. Treatment of atopic eczema with evening primrose oil: rationale and clinical results. Clin Investig 1992; 70: $167-71$

6. Joy CB, Mumby-Croft R, Joy LA. Polyunsaturated fatty acid (fish or evening primrose oil) for schizophrenia. Cochrane Database Syst Rev 2000; (2): CD001257.

7. Belch JJ, Hill A. Evening primrose oil and borage oil in rheumatologic conditions. Am J Clin Nutr 2000; 71(1 Suppl): 352S-6S.

8. Joe LA, Hart LL. Evening primrose oil in rheumatoid arthritis. Ann Pharmacother 1993; 27: 1475-7.

9. Wang W, Chen HS, Liu JP. Evening Primrose Oil or other essential fatty acids for the treatment of pre-menstrual syndrome (PMS). Cochrane Database Syst Rev 2018; 2: CD001123.

10. Budeiri D, Li Wan Po A, Dornan JC. Is evening primrose oil of value in the treatment of premenstrual syndrome? Control Clin Trials 1996; 17: 60-8.
11. Watanabe S, Sakurada M, Tsuji H, Matsumoto S, Kondo K. Efficacy of $\gamma$-linolenic acid for treatment of premenstrual syndrome, as assessed by a prospective daily rating system. J Oleo Sci 2005; 54: $217-24$.

12. Saki M, Akbari S, Saki M, Tarrahi MJ, Gholami M, Pirdadeh S. The effect of primrose oil on the premenstrual syndrome among the female students in Lorestan University of Medical Sciences: a triple blind study. J Nurs Midwifery Sci 2015; 2: 20-6.

13. Gautam S, Srivastava A, Kataria K, Dhar A, Ranjan P, Kumar J. New breast pain chart for objective record of mastalgia. Indian J Surg 2016; 78: 245-8.

14. Graham J, Franks S, Bonney RC. In vivo and in vitro effects of gamma-linolenic acid and eicosapentaenoic acid on prostaglandin production and arachidonic acid uptake by human endometrium. Prostaglandins Leukot Essent Fatty Acids 1994; 50: 321-9.

15. Parveen S, Sarwar G, Ali M, Channa GA. Danazol versus oil of evening primrose in the treatment of mastalgia. Pak J Surg 2007; 23: 10-3.

16. Fathizadeh N, Takfallah L, Ehsanpour S, Namnabati M, Askari S. Effects of evening primrose oil and vitamin $\mathrm{E}$ on the severity of periodical breast pain. Iran J Nurs Midwifery Res 2009; 13: 90-3.

17. Pruthi S, Wahner-Roedler DL, Torkelson CJ, Cha SS, Thicke LS, Hazelton JH, et al. Vitamin E and evening primrose oil for management of cyclical mastalgia: a randomized pilot study. Altern Med Rev 2010; 15: 59-67.

18. Cheung KL. Management of cyclical mastalgia in oriental women: pioneer experience of using gamolenic acid (Efamast) in Asia. Aust N Z J Surg 1999; 69: 492-4.

19. Alvandipour M, Tayebi P, Alizadeh Navaie R, Khodabakhshi H. Comparison between effect of evening primrose oil and vitamin E in treatment of cyclic mastalgia. J Babol Univ Med Sci 2011; 13: 7-11.

20. Saied GM, Kamel RM, Dessouki N. Low intensity laser therapy is comparable to bromocriptine-evening primrose oil for the treatment of cyclical mastalgia in Egyptian females. Tanzan Health Res Bull 2007; 9: 196-201.

21. Goyal A, Mansel RE. A randomized multicenter study of gamolenic acid (Efamast) with and without antioxidant vitamins and minerals in the management of mastalgia. Breast J 2005; 11: 41-7.

22. Sharma N, Gupta A, Jha PK, Rajput P. Mastalgia cured! Randomized trial comparing centchroman to evening primrose oil. Breast J 2012; 18: 509-10.

23. Blommers J, de Lange-De Klerk ES, Kuik DJ, Bezemer PD, Meijer S. Evening primrose oil and fish oil for severe chronic mastalgia: a randomized, double-blind, controlled trial. Am J Obstet Gynecol 2002; 187: 1389-94.

24. Qureshi S, Sultan N. Topical nonsteroidal anti-inflammatory drugs versus oil of evening primrose in the treatment of mastalgia. Surgeon 2005; 3: 7-10. 
25. van der Sluijs CP, Bensoussan A, Liyanage L, Shah S. Women's health during mid-life survey: the use of complementary and alternative medicine by symptomatic women transitioning through menopause in Sydney. Menopause 2007; 14(3 Pt 1): 397-403.

26. Farzaneh F, Fatehi S, Sohrabi MR, Alizadeh K. The effect of oral evening primrose oil on menopausal hot flashes: a randomized clinical trial. Arch Gynecol Obstet 2013; 288: 1075-9.

27. Kollias J, Macmillan RD, Sibbering DM, Burrell H, Robertson JF. Effect of evening primrose oil on clinically diagnosed fibroadenomas. Breast 2000; 9: 35-6.

28. Jamilian M, Afshar R. Effects of combined evening primrose oil and vitamin D intake on hs-CRP, oxidative stress and pregnancy outcomes in women with gestational diabetes. J Arak Univ Med Sci 2017; 19: 43-51.

29. D'Almeida A, Carter JP, Anatol A, Prost C. Effects of a combination of evening primrose oil (gamma linolenic acid) and fish oil (eicosapentaenoic + docahexaenoic acid) versus magnesium, and versus placebo in preventing pre-eclampsia. Women Health 1992; 19: 117-31.

30. Pizzorno JE, Murray MT, Joiner-Bey H. The clinician's handbook of natural medicine. St. Louis: Elsevier Health Sciences; 2016.

31. Diansuy NN, Aguilar AS. The effectiveness of evening primrose oil gel capsule as a cervical ripening agent during labor induction as measured by bishop score on term singleton pregnant patients. Philipp Obstet Gynecol Soc 2017; 41: 1-4.

32. Dove D, Johnson P. Oral evening primrose oil: its effect on length of pregnancy and selected intrapartum outcomes in low-risk nulliparous women. J Nurse Midwifery 1999; 44: 320-4.

33. Vahdat M, Tahermanesh K, Mehdizadeh Kashi A, Ashouri M, Solaymani Dodaran S, Kashanian M, et al. Evening primrose oil effect on the ease of cervical ripening and dilatation before operative hysteroscopy. Thrita 2015; 4: e29876.

34. Tanchoco M, Aguilar AS. Cervical priming prior to operative hysteroscopy: a randomized controlled study comparing the efficacy of laminaria versus evening primrose oil (EPO). J Minim Invasive Gynecol 2015; 22(6S): S45.

35. Jamison JR. Clinical guide to nutrition and dietary supplements in disease management. Amsterdam: Churchill Livingstone; 2003.

36. Stockley IH. Stockley's drug interactions: a source book of interactions, their mechanisms, clinical importance, and management. London: Pharmaceutical Press; 2002.

37. Gardner Z, McGuffin M. American Herbal Products Association's botanical safety handbook. Boca Raton, (FL): CRC Press/Taylor \& Francis; 2013. 